|| Print ISSN: 2589-7837 || Online ISSN: 2581-3935 ||

International Journal of Medical Science and Diagnosis Research (IJMSDR)

Available Online at www.ijmsdr.com

NLM (National Library of Medicine ID: 101738824)

Original Research Article

Volume 6, Issue 2; February: 2022; Page No. 05-08

\title{
COVID 19 \& its Different Colours- An Autobiographical, Case Report of a Physician Suffering Twice with COVID Atypical Symptoms Despite Vaccinated.
}

\author{
Dr Manuj Kumar Sarkar ${ }^{1}$, Dr Upparakadiyala Rakesh² Dr Subhra Dey ${ }^{2}$, \\ Dr Boudhayan Das Munshi ${ }^{4}$ \\ ${ }^{1}$ Associate Professor, Department of General Medicine, All India Institute of Medical \\ Sciences, Deoghar \\ ${ }^{2}$ Assistant Professor, Department of General Medicine, All India Institute of Medical \\ Sciences, Mangalagiri \\ ${ }^{3}$ Professor, Department of Conservative Dentistry and Endodontics \\ ${ }^{4}$ Assistant Professor, Department of General Medicine, All India Institute of Medical \\ Sciences, Deoghar
}

Conflicts of Interest: Nil

Corresponding author: Dr Manuj Kumar Sarkar

DOI: https://doi.org/10.32553/ijmsdr.v6i2.918

\section{Abstract:}

COVID 19 caused by severe acute respiratory syndrome corona virus 2 (SARS CoV2). Initial infection started from China in December 2019. It became pandemic and till date it has infected 399 million people all over the world. First wave was associated with more panic situation and it has impacted mental health globally. As time passed and with subsequent waves, we have learnt to deal with the stress caused by COVID 19. I am presenting my case of suffering from COVID 19 twice despite vaccinated and its psychological impact on mental status.

\section{Introduction:}

COVID 19 (Coronavirus Disease 2019) Caused by Severe Acute Respiratory Syndrome Coronavirus 2 (SARS CoV2). First Case detected in Wuhan China, in $31^{\text {st }}$ December, when an atypical case of pneumonia was admitted in Hospital. Soon the outbreak started spreading. On $5^{\text {th }}$ January 2020, World Health Organisation (WHO) advised to respond on public health measures and recommended to follow protocols and surveillance on acute severe respiratory infection and influenza [1]. COVID 19 has infected 399 million people with casualties of more than 5.75 million till date and it's still rising ${ }^{[2]}$.
Clinical manifestations starting from asymptomatic to fever, cough, loss of smell and taste, pneumonia, acute respiratory distress syndrome (ARDS), diarrhoea, vomiting etc [3,4]. Many atypical presentations are also reported like haemoptysis, pulmonary embolism, cardiac involvement mainly acute viral myopericarditis, acute heart failure, myocardial infarction, neurological manifestations like Guillain barre syndrome (GBS), viral encephalitis, acute toxic and/or necrotising encephalopathy, vestibular neuritis, olfactory and taste disturbances, stroke and non- specific headache and dizziness, gastro-intestinal symptoms like 
anorexia, diarrhoea, vomiting, pain abdomen, ocular manifestations like conjunctivitis, watering from eyes, cutaneous manifestations like skin rashes, urticaria ${ }^{[5,6]}$.

Many variants have arisen till date and caused increase in virulence of the virus and causing three major waves till date ${ }^{[1]}$. Many drugs are being tried for treatment of COVID 19, off level and on compassionate use therapy as hydroxychloroquine, chloroquine, lopinavirritonavir, azithromycin, favipiravir, remdesivir, interferon, convalescent plasma, steroid, anti IL6 inhibitors based on their antiviral property ${ }^{[7]}$. Psychological impact of COVID 19 on general population and particularly health care workers (HCW) working in high-risk areas were high. Studies has shown that HCW suffered from stress, anxiety, depression, sleep disturbance and burnout ${ }^{[8]}$.

The purpose of writing this case report is to share the experiences I (Dr Manuj Kumar Sarkar) gained while suffering from COVID 19 twice despite vaccinated (March-April 2020) and also the difficulties I faced during both the episodes.

\section{Case Presentation:}

During first episode (November 2020): it started with Fever with chills \& rigor 102-104 F, Severe malaise, body ache, palpitation, and severe anxiety. Fever was persistent, continuous, little responsive to antipyretics, used to returned back after 1-2 hours of antipyretic intake, lasted for 6-7 days. Cough started from $3^{\text {rd }}$ day, it was persistent, repetitive, dry, irritative, increasing severity till $10^{\text {th }}$ day, occasional sputum production, improved over next two weeks, but complete resolution took place only after 2-3 months. Body ache, severe myalgia, asthenia was present. There was severe anxiety, palpitation, fear for impending death was very much present till oxygen saturation was normalised. On examination Vital signs were within normal limit. Though saturation started to drop from $97-99 \%$ to $92-94 \%$ on $5^{\text {th }}$ day, it gradually improved over next 2 days. Chest CT (Computed Tomography) on fifth day showed ground glass opacity in both lung fields with CT score of 8. I was hospitalised, treated with oxygen, hydroxychloroquine, ivermectin, dexamethasone, low molecular weight heparin, remdesivir injection, antipyretic, vitamin $\mathrm{C}$, vitamin $\mathrm{D}$, multivitamins, warm water gurgle and steam inhalation. ECG on $6^{\text {th }}$ day showed occasional ventricular ectopic, though biomarkers were within normal limit, I became very stressed and terrified seeing ECG changes, though by God's grace, I could overcome it.

During second episode (December 2021): Though the symptoms were similar mainly Fever, body ache, myalgia, dry cough, tiredness. Fever persisted for 3-4 days, 100$102{ }^{\circ} \mathrm{F}$, it was responsive to antipyretics. I also had cough with occasional sputum production but on $4^{\text {th }}$ day I noticed streaks of blood in phlegm, which persisted till $6^{\text {th }}$ day, I became very tensed seeing blood in sputum, though haematological investigations were within normal limit, it took 20-25 days for the cough for full recovery. Medications used were only symptomatic like antipyretic, antihistaminic, cough syrup, steam inhalation. Many medications Ivermectin, Hydroxychloroquine, dexamethasone, low molecular weight heparin, remdesivir injection, oxygen therapy which were used previously, were not used during second episode.

\section{Significant differences observed in two} episodes:

1) Stress \& Anxiety: Symptoms related to anxiety, fear of death and stress regarding outcome were more during first episode and being a specialist in Medicine, it was more difficult to live those days, when you are aware that there is no proven treatment till date.

2) Polypharmacy: Many drugs were used on during first episode, some off level and 
some on compassionate ground, which were not used during second episode.

3) Mental Strength: From the experiences we gained from fighting against COVID 19 during last 2 years, better immunity due to vaccination or previous infection, mental strength to fight against the disease was much high than the first episode.

4) Severity: The second episode was less severe. Body immunity booster by prior infection and vaccination must have played very important role controlling the disease during second episode.

5) Atypical Symptoms: Cardiac involvement evident from ECG changes during first episode was terrifying and I was fortunate to survive without major complications. Blood mixed sputum during second episode was an atypical and rare presentation during second episode, again I was fortunate to survive without major damage.

\section{Discussion:}

Respiratory outbreaks has tremendous impact on mental health on individual, health care workers (HCW's) are more prone for mental illness including anxiety, depression, posttraumatic stress disorder, absenteeism from duty more in HCW's who were taking care of infected patients and were in direct contact with patients ${ }^{[8,9]}$. As I was in direct contact with patients and was working as front line HCW, I was prone to stress and burnout. The most common groups of people vulnerable for mental health related issues are doctors, Nurses and other health care workers, elderly people, children, college students, homeless people, patients with psychiatric illness ${ }^{[10]}$. As compared previous viral outbreaks like SARS (severe acute respiratory syndrome), MERS (Middle East Respiratory Syndrome Virus), which were predominantly prevalent in hospital environment, COVID 19 has involved broader part of community and fear and uncertainty related to COVID 19 remains to be very high. Moreover, frontline health care workers are more prone for psychological impact compared to others ${ }^{[8,9]}$.

Since the beginning of pandemic, treatment of COVID 19 was based on prior experience with corona viral disease, but evidence was lacking their usefulness in COVID 19. Many drugs were tried for treatment of COVID 19 on compassionate ground ${ }^{[11-15]}$.

\section{Conclusion:}

COVID 19, since its appearance, we have seen many faces of it. Many patients presented with typical and atypical symptoms. Initially we did not know how to deal with it. Therefore, anxiety and stress associated with COVID 19 in the initial days was tremendous. Psychological effect of COVID 19 on the patients and their family members was very much, but with time we have learnt live with COVID 19.

\section{Contribution:}

I am very much thankful to my co-authors who were my treating physicians, who took care of me during my illness and under whose treatment and counselling I could overcome my illness. All the authors equally contributed while writing the manuscript.

\section{References:}

1. Sarkar, M. K., Dey, S., \& Munshi, B. D. (2021). "COVID 19- Two Waves \& More" What Have We Learnt? International Journal of Medical Science and Diagnosis Research, 5(12).

https://doi.org/10.32553/ijmsdr.v5i12.885

2. https://www.who.int/emergencies/diseases /novel-coronavirus-2019

3. Su WL, Lu KC, Chan CY, Chao YC. COVID-19 and the lungs: A review. J Infect Public Health. 2021 Nov;14(11):1708-1714. doi: 10.1016/j.jiph.2021.09.024. Epub 2021 Oct 2. PMID: 34700289; PMCID: PMC8486577. 
4. Shi Y, Wang G, Cai XP, Deng JW, Zheng L, Zhu HH, Zheng M, Yang B, Chen Z. An overview of COVID-19. J Zhejiang Univ Sci B. 2020 May;21(5):343-360. doi: 10.1631/jzus. B2000083. Epub 2020 May 8. PMID: 32425000; PMCID: PMC7205601.

5. Abobaker A, Raba AA, Alzwi A. Extrapulmonary and atypical clinical presentations of COVID-19. J Med Virol. 2020 Nov;92(11):2458-2464. doi: 10.1002/jmv.26157. Epub 2020 Jun 29. PMID: 32520401; PMCID: PMC7300507.

6. Babu TA, Sarkar MK, Sharmila V. COVID-19 vestibular neuritis (CVN) in a healthcare worker: a rare complication of COVID-19 infection. J R Coll Physicians Edinb. 2021 Jun;51(2):199-207. doi: 10.4997/JRCPE.2021.224. PMID: 34131685.

7. Kalil AC. Treating COVID-19-Off-Label Drug Use, Compassionate Use, and Randomized Clinical Trials During Pandemics. JAMA. 2020;323(19):18971898. doi:10.1001/jama.2020.4742

8. Danet Danet A. Psychological impact of COVID-19 pandemic in Western frontline healthcare professionals. A systematic review. Med Clin (Barc). 2021 May 7;156(9):449-458. English, Spanish. doi: 10.1016/j.medcli.2020.11.009. Epub 2021 Jan 1. PMID: 33478809; PMCID: PMC7775650.

9. Brooks S. K., Webster R. K., Smith L. E., Woodland L., Wessely S., Greenberg N., et al. (2020). The psychological impact of quarantine and how to reduce it: rapid review of the evidence. Lancet 395912 $920 . \quad 10.1016 / \mathrm{S} 0140-6736(20) 30460-$ 8 [PMC free article] [PubMed] [CrossRef] [Google Scholar]
10. Pedrosa AL, Bitencourt L, Fróes ACF, Cazumbá MLB, Campos RGB, de Brito SBCS, Simões E Silva AC. Emotional, Behavioral, and Psychological Impact of the COVID-19 Pandemic. Front Psychol. 2020 Oct 2; 11:566212. doi: 10.3389/ fpsyg.2020.566212. PMID: 33117234; PMCID: PMC7561666.

11. Kalil AC. Treating COVID-19-Off-Label Drug Use, Compassionate Use, and Randomized Clinical Trials During Pandemics. JAMA. 2020;323(19):18971898. doi:10.1001/jama.2020.4742

12. U.S Food \& Drug Administration. FDA approves first treatment for covid19. https://www.fda.gov/news-events/ press-announcements/fda-approves-firsttreatment-covid-19 (accessed Nov 11, 2020).

13. Cao B.; Wang Y.; Wen D.; et al. A Trial of Lopinavir-Ritonavir in Adults Hospitalized with Severe Covid-19. N. Engl. J. Med. 2020, 382 (19), 1787-1799. 10.1056/NEJMoa2001282. [PMC free article] [PubMed] [CrossRef] [Google Scholar]

14. Gao J.; Tian Z.; Yang X. Breakthrough: Chloroquine phosphate has shown apparent efficacy in treatment of COVID19 associated pneumonia in clinical studies. BioSci. Trends 2020, 14 (1), 7273. 10.5582/bst.2020.01047. [PubMed] [CrossRef] [Google Scholar]

15. Xing K, Tu XY, Liu M, Liang ZW, Chen JN, Li JJ, Jiang LG, Xing FQ, Jiang Y. Efficacy and safety of COVID-19 vaccines: a systematic review. Zhongguo Dang Dai Er Ke Za Zhi. 2021 Mar;23(3):221-228. doi: 10.7499/j.issn. 1008-8830.2101133. PMID: 33691913; PMCID: PMC7969187. 